\title{
Intranasal Pleomorphic Adenoma
}

\section{Venkatesh Manikrao Patil, Rashmi Mallanagouda Patil, Anirudha Vasant Kushtagi}

\begin{abstract}
Pleomorphic adenoma is a benign tumor arising from major salivary glands and also has been reported in salivary glands of palate rarely in nasopharynx, oropharynx and larynx and lacrimal glands. We report a case pleomorphic adenoma of nasal septum and discuss the clinical features, management along with review of literature.
\end{abstract}

Keywords: Pleomorphic adenoma, Nasal septum, Minor salivary glands.

How to cite this article: Patil VM, Patil RM, Kushtagi AV. Intranasal Pleomorphic Adenoma. Int J Otorhinolaryngol Clin 2013;5(3):164-165.

\section{Source of support: Nil}

Conflict of interest: None declared

\section{INTRODUCTION}

Pleomorphic adenoma of the nasal septum is a rare benign tumor. Oral cavity forms the frequent site for pleomorphic adenoma next to major salivary glands. Even though nasal cavity has numerous serous and mucous glands, incidence of pleomorphic adenoma is rare. We present an unusual case of intranasal pleomorphic adenoma.

\section{CASE REPORT}

A female patient aged presented with history of nasal blockage, watery discharge and mass in right nasal cavity since 3 months. Mass has gradually increased in size. On anterior rhinoscopy pale polypoidal mass seen arising in region just behind nasal valve region measuring $1 \times 1 \mathrm{~cm}$ situated on septum, mass was sensitive to touch, does not bleeds to touch probing could be done all around swelling except medial surface were its attached to septum (Fig. 1).

Case was taken for surgical excision and biopsy under guidance of endoscopy mucoperichondrial flap around the mass is elevated along with the growth. Complete excision of the mass with clear margin was done (Fig. 2).

Histopathological examination section showed tissue lined by stratified squamous epithelium. Subepithelium showed tissue comprised of epithelial and stromal component with impression of pleomorphic adenoma (Fig. 3). Subsequent follow-up of patient revealed no fresh complaints or recurrence were noted after 6 months. Patient has been advised for regular follow-up to detect any recurrence every 3 months.

\section{DISCUSSION}

Pleomorphic adenoma is commonest benign tumor of major salivary gland. ${ }^{1}$ Majority of intranasal pleomorphic adenoma occurs in 3rd to 6th decade and most commonly seen in females. Patients present with symptoms of unilateral nasal obstruction, nasal mass, epistaxis, epiphora and rhinorrea. Clinical examination shows polypoidal grey white mass with well-defined capsule with firm consistency. Etiology of adenoma has been speculated from vomeronasal or Jacobson's organ by Stevenson1932, however sections shows no elements which could be attributed to the vomeronasal nasal organ Kamal1984. ${ }^{2}$ Matthew et al $1944^{3}$ suggested the origin from displaced embryonic ectodermal epithelial cells which are carried via the nasal pits into septal region. Evans and Cruickshank in $1970^{4}$ claimed that these tumors are entirely epithelial tumors and that they arise in fully developed salivary gland tissue. Histologically adenoma of septum differs from major salivary gland by being highly cellular (epithelial) with little or no stromal component. ${ }^{5}$ Because of lack of stromal component, histologically they resemble aggressive epithelial tumors. Incidence of these has been reported as adenoid cystic carcinomas on basis of tissue biopsy have been present Haberman. ${ }^{6}$ Myoepithelial cellularity is unusually increased in these tumor compared with major salivary gland tumors. Occasionally, small acini or duct like structures filled with secretions are present along perimeters of the more cellular foci. Infrequently chondroid myxoid or collagenous stroma predominate resemblance to traditional mixed tumor. Malignant change occurs extremely rare. Freeman ${ }^{7}$ reported a case of histologically benign recurrent pleomorphic adenoma of septum with cervical metastasis. Two cases were reported with carcinoma expleomorphic adenoma of septum by Cho et al. ${ }^{8}$

Differential diagnosis of the intranasal tumors includes benign or malignant tumors such as cartilaginous tumors from the nasal septum, squamous cell carcinoma, adeno carcinoma, inverted papilloma, schwannoma, sinonasal melanoma, osteoma hemangiomas angiofibroma.

Computed tomography (CT) scan images helps in detection extent of lesion and planning of treatment. Erosion of bone, cartilage, presence of calcification suggests malignant neoplasm management of these tumors is either by wide local excision or radical procedure. Many authors 


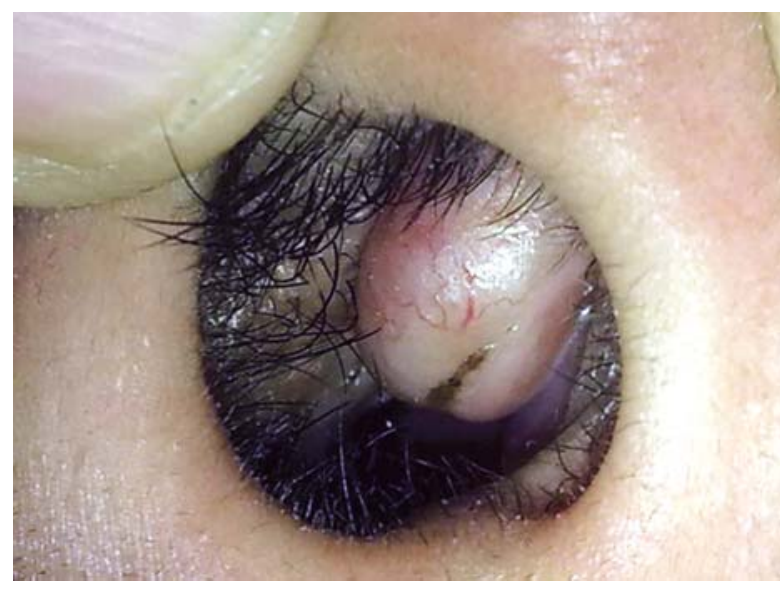

Fig. 1: Polypoidal mass seen in right nasal cavity

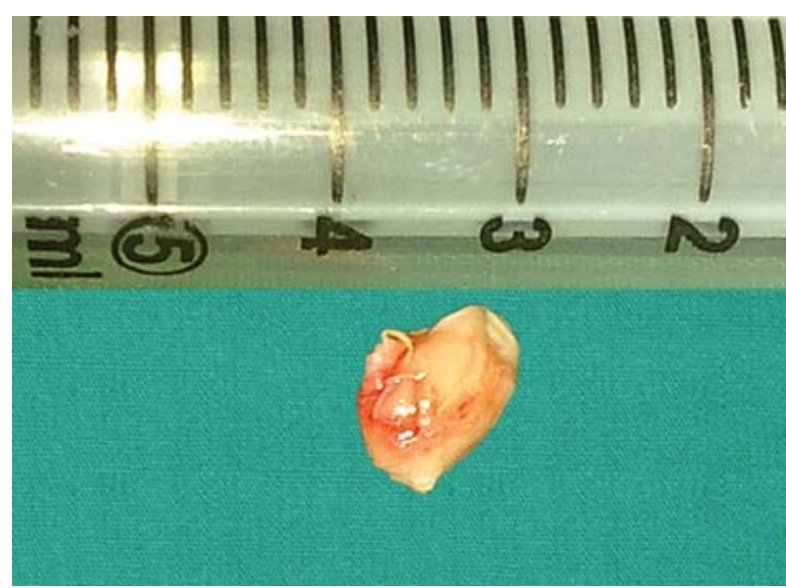

Fig. 2: Excised specimen sent for histopathological examination

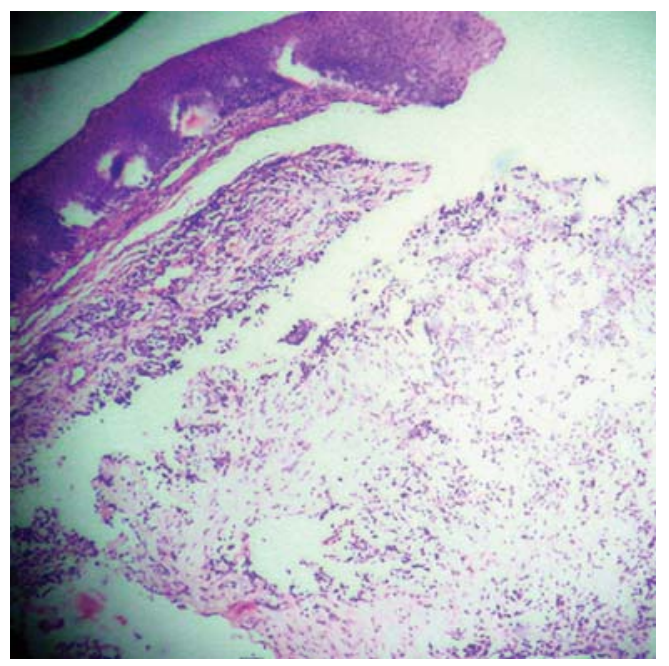

Fig. 3: Histopathological slide showing evidence pleomorphic adenoma

with cases report in literature Freeman (1950), Wallaec (1990) suggest local but with clear adequate margin has treatment of choice, use of radical procedures to prevent recurrence are unwarranted. External rhinotomy approach has been usual approach for complete removal of tumor. But with help of nasal endoscopy complete clearance of disease with less morbidity can be obtained. We used intranasal endoscopic approach for complete excision of lesion which reduce morbidity and early postoperative discharge. Pleomorphic adenomas have a low recurrence rate compared with that of intraoral tumors Bergstrom (1981). ${ }^{9}$ Adenoma with myxoid stroma which could be easily spilled into surgical field, provide a nidus for recurrence hence lesion with myxoid stromal predominance have contributed for recurrence.

\section{CONCLUSION}

We suggest use of nasal endoscopy for complete clearance of disease under direct visualization. Pleomorphic adenoma is to be included in differential diagnosis of nasal polyp.

\section{ACKNOWLEDGMENTS}

The authors are thankful for all the assistance and support from Dr NH Kulkarni, Dr Sharan Badiger and other staff of BLDE University, Shri BM Patil Medical College, Bijapur, India.

\section{REFERENCES}

1. Stevenson HN. Mixed tumor of the septum. Ann Otol Rhinol Laryngol 1932;41:563-570.

2. Kamal SA. Pleomorphic adenoma of the nose: A clinical case and historical review. J Laryngol Otol 1984;98:917-923.

3. Matthew S, Ersner MD, Saltzmann M. A mixed tumor of the nasal septum. Report of a case. Laryngoscope 1944;54:287-296.

4. Evans RW, Cruickshank AH. Epithelial tumors of the salivary glands. Major problems in pathology. Philadelphia, PA: WB Saunders Co. 1970. 167 p.

5. Compagno J, Wong RT. Intranasal mixed tumors (pleomorphic adenomas): A clinicopathologic study of 40 cases. Am J Clin Pathol 1977;68:213-218.

6. Haberman RS 2nd, Stanley DE. Pleomorphic adenoma of the nasal septum. Otolaryngol Head Neck Surg 1989;100:610-612.

7. Freeman SB, Kennedy KS, Parker GS, Tatum SA. Metastasizing pleomorphic adenoma of the nasal septum. Arch Otolaryngol Head Neck Surg 1990;116:1331-1333.

8. Cho KJ, el-Naggar AK, Mahanupab P, Luna MA, Batsakis JG. Carcinoma ex-pleomorphic adenoma of the nasal cavity: A report of two cases. J Laryngol Otol 1995;109:677-679.

9. Bergstrom B, Biorklund A. Pleomorphic adenoma of septum. J Laryngol Otol 1981;95:179-181.

\section{ABOUT THE AUTHORS}

\section{Venkatesh Manikrao Patil (Corresponding Author)}

Assistant Professor, Department of Otorhinolaryngology, Shri BM Patil Medical College, BLDE University, Bijapur, Karnataka, India e-mail: venkat27mp@rediffmail.com

\section{Rashmi Mallanagouda Patil}

Senior Resident, Department of Surgery, Shri BM Patil Medical College, BLDE University, Bijapur, Karnataka, India

\section{Anirudha Vasant Kushtagi}

Assistant Professor, Department of Pathology, Shri BM Patil Medical College, BLDE University, Bijapur, Karnataka, India 